\title{
Fünf Sterne nach klinischer Untersuchung
}

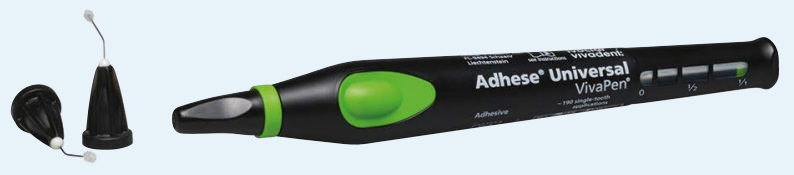

chung zur Verfügung. Die Resultate: $99 \%$ waren nach einem Jahr Tragezeit noch in situ. 95\% der Restaurationen zeigten keinerlei Anzeichen einer Randverfärbung. Hin-

Das renommierte US-amerikanische Fachmagazin „The Dental Advisor“ hat dem Universal-Adhäsiv Adhese Universal von Ivoclar Vivadent ein ausgezeichnetes klinisches Rating von 99\% nach 1 Jahr bescheinigt. Die Ausgangslage: Im Rahmen einer klinischen Untersuchung ließen die Anwender ihren Probanden 83 direkte und indirekte Restaurationen mit dem Produkt einsetzen. Das Adhäsiv kam dabei in allen Restaurationsklassen zur Anwendung. 73 der eingesetzten Restaurationen standen nach 1 Jahr für die Nachuntersu- zu kommt: Bei keinem einzigen der Probanden traten postoperative Sensibilitäten auf. „Excellence - 5 Stars“ lautete daher das Rating des „Dental Advisor“. Die Anwender lobten bei dieser Gelegenheit die Vielseitigkeit des Adhäsivs, das sich sowohl für die Self-Etch- als auch für die Total-Etch-Technik eignet. Auch die praktische Anwendung des VivaPen-Dosiersystems kam bei den Testern gut an.

Nach einer Pressemitteilung der Ivoclar Vivadent GmbH, Ellwangen (Jagst) www.ivoclarvivadent.de 